\title{
Complete genetic organization and functional aspects of the Escherichia coli S fimbrial adhesin determinant: nucleotide sequence of the genes sfa B, C, D, E, F
}

\author{
Thomas Schmoll, ${ }^{1 *}$ Joachim Morschhäuser, ${ }^{1}$ Manfred Ott, ${ }^{1}$ Birgit Ludwig,' \\ Irma van Die ${ }^{2}$ and Jörg Hacker't \\ 'Institut für Genetik und Mikrobiologie, University of Würzburg, Röntgenring 11, \\ D-8700 Würzburg. Germany and ${ }^{2}$ Department of Molecular and Cellular Biology, \\ University of Utrecht, Palualaan 8, CH 3584 Utrecht, The Netherlands
}

(Received June 5, 1990; accepted in revised form August 14, 1990)

Schmoll, T. (Institut für Genetik und Mikrobiologie, University of Würzburg, Röntgenring 11, D-8700, Würzburg, Germany), J. Morschhäuser, M. Ott, B. Ludwig, I. van Die and J. Hacker. Complete genetic organization, and functional aspects of the Escherichia coli S fimbrial adhesin determinant: nucleotide sequence of the genes sfa B, C, D, E, F. Microbial Pathogenesis 1990; 9: $331-343$.

The $S$ fimbrial adhesin ( $s f a$ ) determinant of $E$. coli comprises nine genes situated on a stretch of 7.9 kilobases $(\mathrm{kb})$ DNA. Here the nucleotide sequence of the genes sfa B and sfa C situated proximal to the main structural gene sfaA is described. Sfa-LacZ fusions show that the two genes are transcribed in opposite directions. The isolation of mutants in the proximal region of the sfa gene cluster, the construction of sfa-phoA gene fusions and subsequent transcomplementation studies indicated that the genes sfa $\mathrm{B}$ and sfa $\mathrm{C}$ play a role in regulation of the sfa determinant. In addition the nucleotide sequence of the genes sfa D, sfaE and sfa F situated between the genes sfaA and sfa G responsible for $S$ subunit proteins, were determined. It is suggested that these genes are involved in transport and assembly of fimbrial subunits. Thus the entire genetic organization of the sfa determinant is presented and compared with the gene clusters coding for P fimbriae (pap), F1C fimbriae (foc) and type I fimbriae (fim). The evolutionary relationship of fimbrial adhesin determinants is discussed.

Key words: Escherichia coli; S fimbrial adhesin (Sfa); genetic organization; gene regulation; nucleotide sequence.

\section{Introduction}

Adhesion of Escherichia coli to eukaryotic cells is a prerequisite for colonization of host tissues, leading to extraintestinal infections (urinary tract infection, sepsis, meningitis) ${ }^{1,2}$ The adhesion is often mediated by bacterial cell appendages, called fimbrial adhesins. Receptors on the host cells are recognized by these organelles, which are proteinaceous heteropolymers, consisting mainly of a structural protein (major subunit). Minor subunits incorporated into the fimbrial rod confer the adhesive properties. ${ }^{3,4}$ The various fimbrial adhesin types can be distinguished by their receptor

\footnotetext{
- Present address: Department of Pathology, University of Cambridge. Tennis Court Road, Cambridge, U.K.

t Author to whom correspondence should be addressed.
} 
specifities. ${ }^{4,5}$ In extraintestinal $E$. coli, type 1, P, S, and F1C fimbrial adhesins are the most commonly found. ${ }^{2,4,5}$ The corresponding gene clusters have been cloned from the chromosomes of various $E$. coli strains and analysed in the last years ${ }^{3.4 .6-9}$ (for review see Hacker ${ }^{4}$ ).

$S$ fimbrial adhesins (Sfa) mediate adhesion to sialic acid-containing receptors. ${ }^{10}$ The sfa determinant has been cloned from a urinary tract isolate and analysed in detail. ${ }^{6.11-14}$ It was shown that the $S$ fimbrial adhesin complex consists of four proteins; $\mathrm{SfaA}$ representing the major fimbrillin protein and $\mathrm{SfaG}, \mathrm{SfaS}$ and $\mathrm{SfaH}$, the minor subunits. The corresponding genes were analysed and sequenced, ${ }^{11.13}$ and SfaS was determined as the sialic-binding S-specific adhesin. ${ }^{10,14}$ It was further shown that the expression of S fimbriae highly depends on environmental conditions. ${ }^{15}$ In this report we present the nucleotide sequences of another five sfa-specific genes and show that the genes sfa $\mathrm{B}$ and $s f a \mathrm{C}$ situated proximally to the major subunit gene sfa $\mathrm{A}$ play a role in the regulation of the sfa determinant. Furthermore the entire genetic organization of the sfa gene cluster is presented and aspects of the evolution of fimbrial adhesins are discussed.

\section{Results}

\section{Nucleotide sequence of $\mathrm{sfa} B$ and $\mathrm{sfa} C$}

In previous reports ${ }^{11.13,14}$ we have determined the DNA sequences of the genes sfaA, sfa G, sfaS and sfa $\mathrm{H}$ coding for the major and minor subunits of the $\mathrm{S}$ fimbrial adhesin complex. The genes are situated between map position 2.3 and $2.8 \mathrm{~kb}(\mathrm{sfa} A)$, and 6.6 and $9.0 \mathrm{~kb}$ (sfa G, S, H) in Fig. 1 (a). In order to get a complete picture of the sfa gene cluster we have sequenced the DNA regions between 0.6 and $2.1 \mathrm{~kb}$ as well as between 2.8 and $6.6 \mathrm{~kb}$. The sequencing strategy is given in Fig. 1 (b).

As shown in Fig. 2 the sequence proximal to sfaA covers a stretch of $1.4 \mathrm{~kb}$. This sequence contains two open reading frames (ORFs). One ORF starts at an ATG codon at position 663-665 and ends at a TAA stop codon at position 990-992. The second ORF runs in the opposite direction, and the coding sequence is therefore on the

(a)

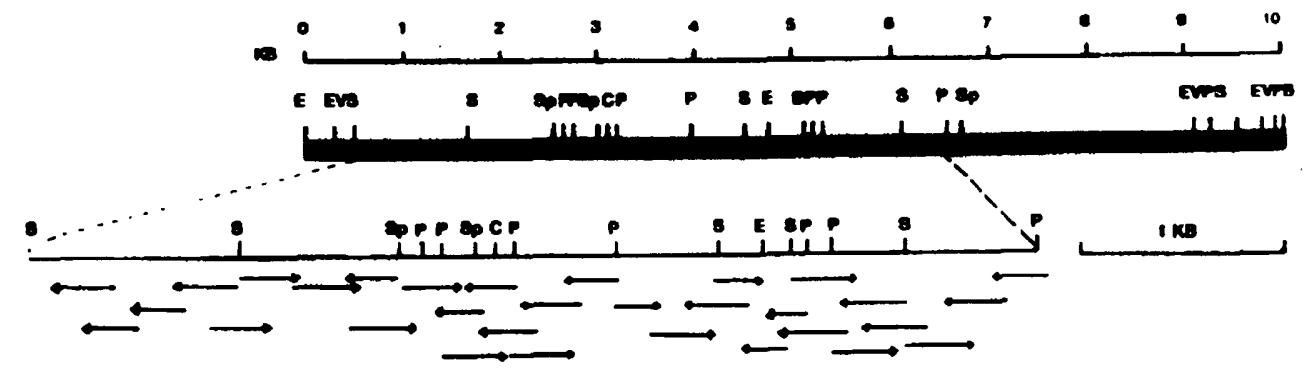

(c)

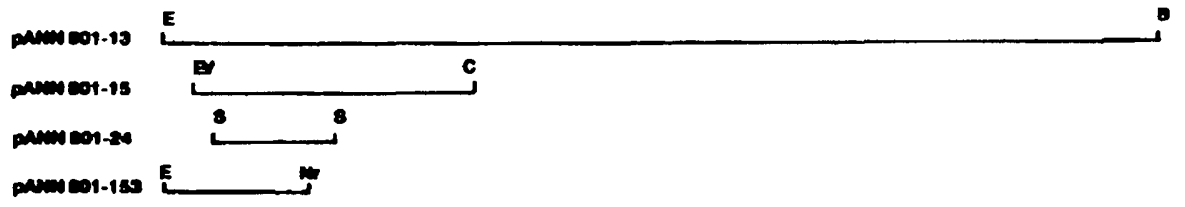

Fig. 1. (a) Restriction map of the sfa specific DNA region (see Hacker et al. ${ }^{6}$ ). (b) Strategy of sequencing of the proximal and internal part of the sfa region, comprising genes sfa $C, B$ and sfaD, E, F, respectively (see Fig. 2 and Fig. 5). Arrows indicate the regions that have been sequenced. (c) Subclones of the sfaregion used. Restriction enzymes are abbreviated as follows: E, EcoRI; EV, EcoRV; S, Smal; Sp, Sphl; P, Pstl; C, Clal; B, BamHI; Nr, Nrul. 


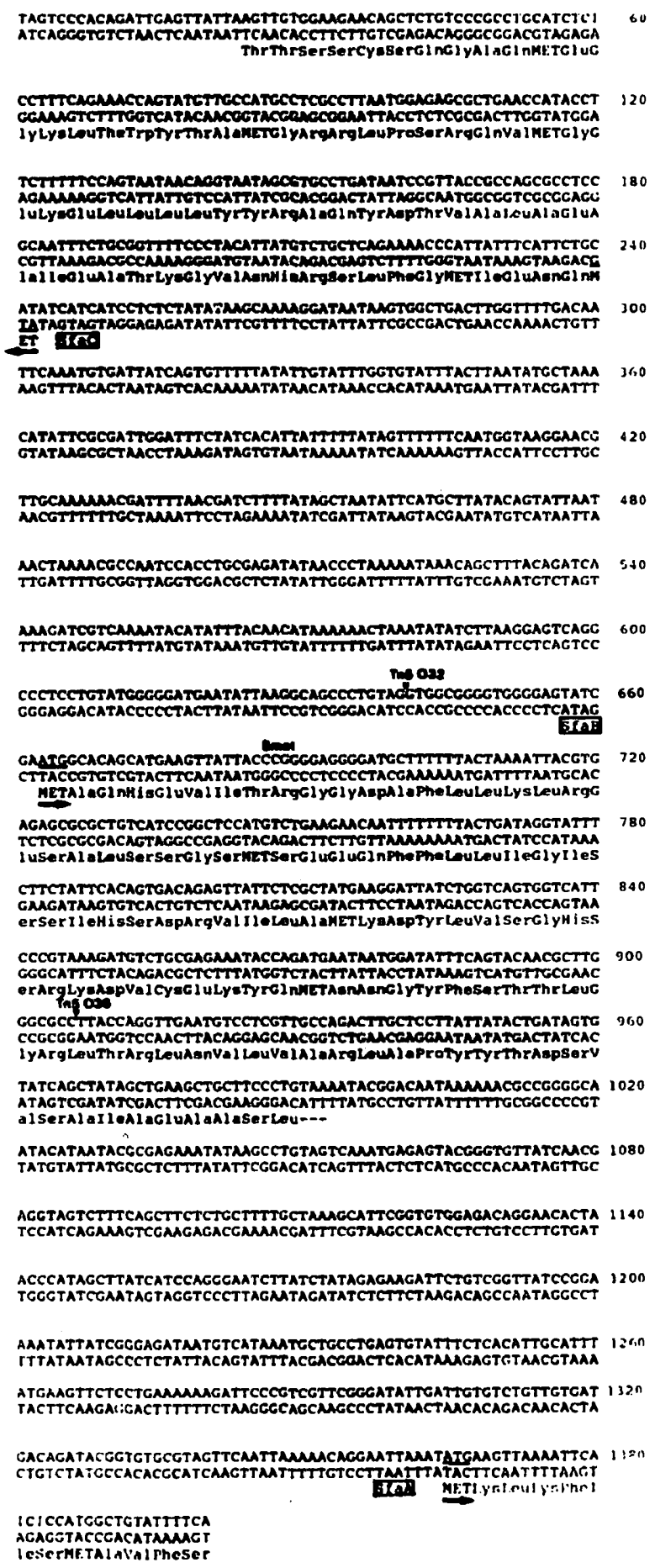

Fig. 2. Nucleotide sequence of the proximal part of the sfa determinant, comprising genes sfa B and sfa C. Amino acid residues are given below. The positions of integration of Tn5 transposons are indicated by triangles.

antiparallel strand. Starting at an initiation codon at map position 238-240 the ORF stops at map position 23-21. The two ORFs which may correspond to two genes were preliminary termed $s f a B$ and $s f a C$. The putative molecular masses of the two gene products $\mathrm{SfaB}$ and $\mathrm{SfaC}$ calculated from the nucleotide sequence were $12.0 \mathrm{kDa}$ (SfaB) and $8.3 \mathrm{kDa}(\mathrm{SfaC})$. 


\section{Localization of Tn5 mutants}

Transposon mutants pANN 801-13/Tn5-014, pANN 801-13/Tn5-032 and pANN 801-13/Tn5-036 which carry Tn5 elements inserted into the proximal sfa region located on the recombinant plasmid pANN 801-13 were isolated previously. ${ }^{6}$ These mutants were negative for $S$ fimbrial formation $\left(\mathrm{Fim}^{-}\right)$as well as for $\mathrm{S}$ specific mannose-resistant hemagglutination ( $\left.\mathrm{Mrh}^{-}\right)$. It was shown by DNA sequence studies that the Tn5-mutant pANN 801-13/Tn5-041 carries the transposon inserted into the gene sfaA, 336 bp downstream of the first nucleotide of the gene (see Schmoll et al. ${ }^{13}$ ). In the mutants pANN 801-13/Tn5-036 and pANN 801-13/Tn5-032 Tn5 transposons are inserted into the gene sfa B at position 906 and 23 bp upstream of the first codon of sfa B at position 640, respectively (see Fig. 2). The location and the phenotypic characterization of these mutants suggest that the genes situated in the proximal region of the sfa determinant play a role in regulation.

\section{Isolation of Sfa-LacZ protein fusions}

In order to analyse the gene products $\mathrm{SfaB}$ and $\mathrm{SfaC}$ and to confirm the direction of transcription of the proximal part of the sfa determinant, Sfa-LacZ translational fusions were isolated. $\lambda$ p/acMu3 phages were randomly inserted into $E$. coli K-12 clones carrying the recombinant plasmids pANN 801-15 and pANN 801-24 [Fig. 1(c)]. The map positions of the insertions and the orientations of the inserted lac $Z$ genes were determined by suitable cleavages with restriction enzymes. The $\beta$-galactosidase activities of the strains harbouring the fused DNA were analysed. As indicated in Fig. 3 , four Lac-positive SfaC-LacZ fusions were isolated. The orientation of insertion of the lac Z genes was from right to left while all insertions in the left to right orientation were LacZ-negative. Other LacZ-positive transductants were isolated following

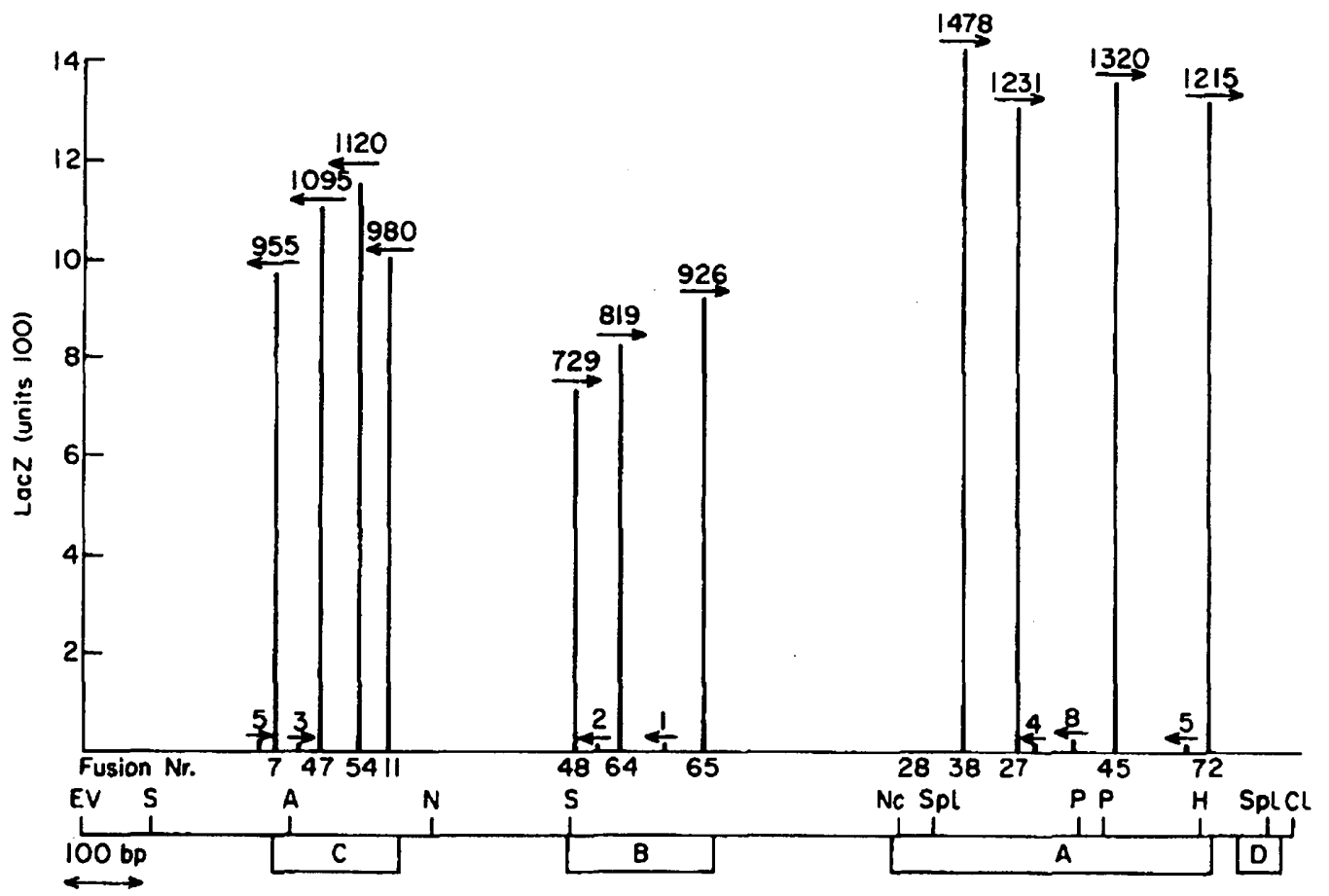

Fig. 3. Analysis of Sfa-LacZ translational fusions of genes sfa C, B, and A following insertion of $\lambda$ plac Mu3 phages. The map position of the sfa specific genes is given in the lower part. Orientations of the fusions are indicated by an arrow. The amount of $\beta$-galactosidase activity is shown graphically, with Lac $Z$ values given on top and the fusion numbers indicated below. MC 4100 was used as the host strain. Restriction enzymes are abbreviated as follows: EV. EvoRV; S. Smal; A, Aval; N. Nrul; Nc, Ncol; Spl, Sphl; P. Pstl; H, Hincll; $\mathrm{Cl}, \mathrm{Clal}$. 
insertion of $\lambda$ placMu3 phages into the coding regions of $s f a \mathrm{~B}$ and $s f a \mathrm{~A}$. In all cases the direction of the lac $Z$ reading frame was from left to right, i.e. the opposite direction to that detected for the SfaC-LacZ fusions. Right to left insertions were LacZ-negative. These results clearly show that the sfa $\mathrm{C}$-specific and sfa B-specific ORFs are translated in vivo. The data further demonstrate that the transcription of sfa $\mathrm{C}$ runs in the opposite direction to sfa $\mathrm{B}$ and $s f a \mathrm{~A}$, which is in good agreement with the sequence data (see Fig. 2).

\section{Cloning of sfa specific sequences into the promoter probe vector $p C B 267$}

To get information on the presence of promoter regions situated in front of the genes sfa $\mathrm{C}$, sfa $\mathrm{B}$ and sfaA, suitable DNA fragments were cloned into the promoter probe vector pCB267..$^{16}$ The strength of putative promoter regions was measured on the basis of the production of alkaline phosphatase (PhoA units). ${ }^{17}$ As indicated in Fig. 4 the construct pTTS 267-69 (sfaA-phoA, B, $\mathrm{C}^{-}$) produced 80 units PhoA (Fig. 4, row 5 ) indicating the existence of a weak but clearly detectable promoter in front of the sfa $\mathrm{A}$ gene. The activity of the promoters in front of sfa $\mathrm{B}$ and $s f a \mathrm{C}$ was determined by the use of the recombinant plasmids pTTS267-1/5 (sfaB-phoA, $\mathrm{A}^{-}, \mathrm{C}^{-}$) and pITS267-1/8 (sfaC-phoA, $A^{-}, B^{-}$) which were able to produce PhoA values of 488 and 429 units (Fig. 4, rows 6,8 ). In all cases the strains used as controls were negative for PhoA production. The putative promoter regions in front of sfa $\mathrm{C}, s f a \mathrm{~B}$ and $s f a \mathrm{~A}$ were preliminarily termed $P_{A}, P_{B}$ and $P_{C}$. A computer search for promoter consensus sequences revealed good -10 and -35 boxes in front of the genes sfa $C$ and sfa $B$ at map positions 272 to 300 bp and 561 to 589 bp, respectively (Fig. 2).

\section{Role of SfaB and SfaC in expression of the sfa determinant}

To define the role of $\mathrm{SfaB}$ and $\mathrm{SfaC}$ in the expression of the sfa gene cluster we used sfa-phoA constructs in trans-complementation tests with $\mathrm{SfaA}^{+}, \mathrm{B}^{+}, \mathrm{C}^{+}$(pANN801 15) and $\mathrm{SfaC}^{+}$(pANN801-153) plasmids. The different DNA constructs were able to co-replicate in the same cell because the sfa-phoA hybrid plasmids carry pBR322 sequences whereas pANN801-15 and pANN801-153 used for complementation consist of the vector molecule pACYC184 together with sfa-specific insert DNA.

As shown in Fig. 4 (row 5 ) the gene products $S f a B$ and SfaC have no effect on the promoter $P_{A}$. In contrast $S f a B$ and $S f a C$ positively influence the activity of the promoters $P_{B}$ and $P_{C}$. Using a SfaC ${ }^{-}, S$ SfaB $^{+}, \mathrm{SfaA}^{-}$PhoA specific construct (pTTS267-282, Fig. 4, row 4) the SfaC coding DNA increases the PhoA production after transcomplementation by a factor of two. SfaC, however, has no effect on its own promoter $P_{C}$ (data not shown). As also indicated in Fig. 4, SfaB has a more pronounced effect on $P_{B}$ (row 3) and $P_{C}$ (row 8). Since $S f a B$ and $S f a C$ do not inflence $P_{A}$ (Fig. 4, row 5 , see above) the increase of expression of sfa $A$ by the action of SfaB and SfaC must result from a transcript which starts at promoter $P_{B}$ (Morschhäuser and Hacker, unpublished data). The major subunit SfaA has no influence on the regulation of the sfa determinant (Fig. 4, Schmoll and Hacker, unpublished data). Thus both gene products, $\mathrm{SfaB}$ and $\mathrm{SfaC}$, are able to stimulate the expression of the sfa determinant in trans.

\section{Nucleotide sequence of $\mathrm{sfa} D, \mathrm{sfa} E$ and $\mathrm{sfa} F$}

To complete the picture of the genetic organization of the sfa determinant the DNA region between the $3^{\prime}$-end of $s f a A$ at position $2.8 \mathrm{~kb}$ and the $5^{\prime}$-end of sfa $\mathrm{G}$ at position $6.6 \mathrm{~kb}$ (Fig. 1) was sequenced. As indicated in Fig. 5, three open reading frames were found. The first ORF (left to right direction) starts at position 118-120 with an ATG codon and stops at position 655-657 with TAA. Downstream, in near vicinity, a 


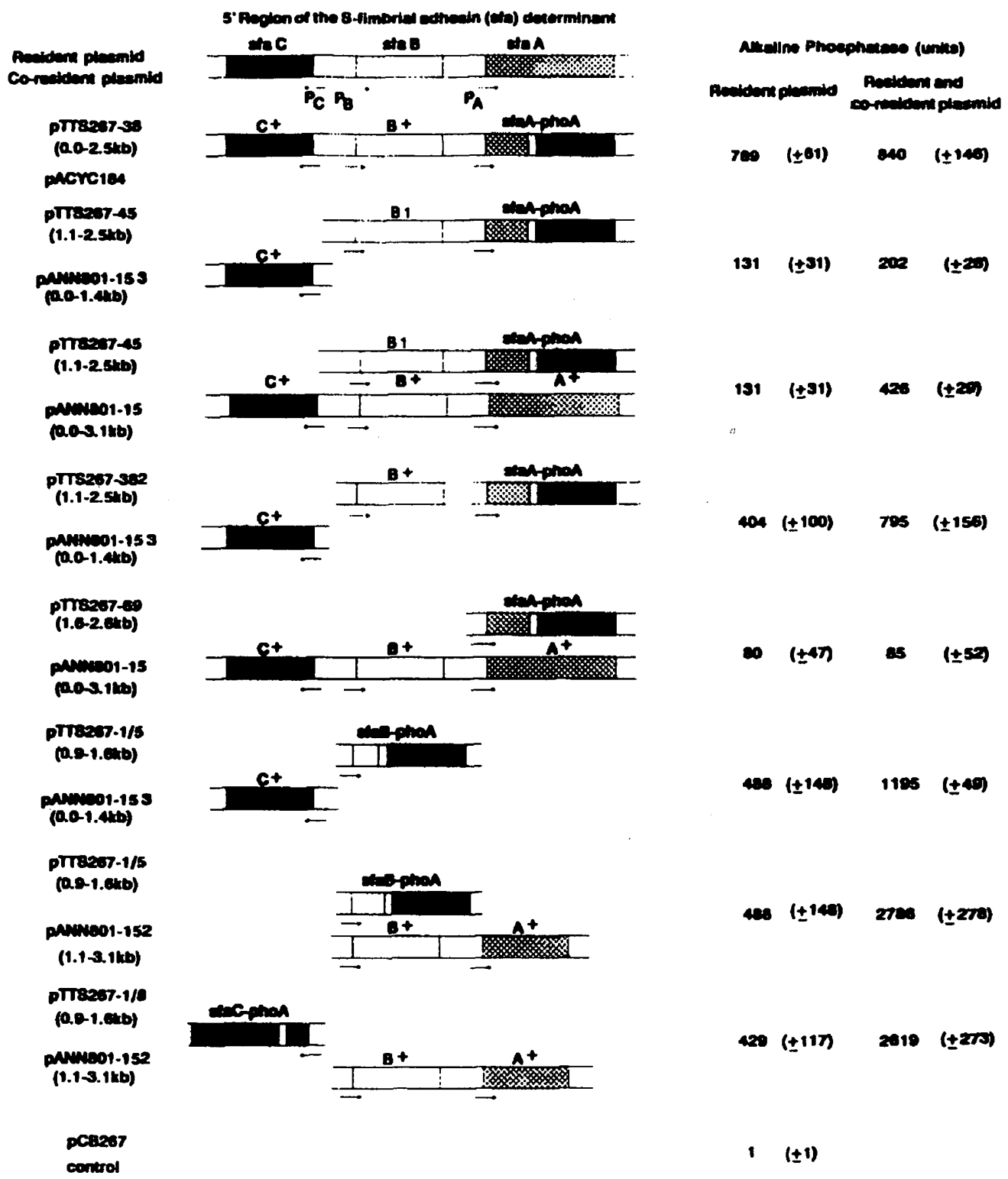

Fig. 4. Transcriptional fusions of sfa specific sequences and the phoA gene. The coordinates of the sfa specific sequences are indicated in Fig. 1. For trans-complementations the plasmids pANN801-15, pANN801-153 and pACYC184 (as a control) were used. CC118 was used as the host strain and CC118 ( $p C B 267$ ) as a phoA-negative control. PhoA units are given as mean \pm standard deviation.

second ORF begins at position 698-701 with ATG, and ends at position 1391-1393 with a TAA stop codon. The third ORF starts at position 1464-1466 with ATG and stops at position 4076-4078, ending with TAA.

These three ORFs are estimated to represent the sfa-specific proteins SfaD, E, and F. By calculation of molecular masses of these ORFs from sequence data, proteins of 17.4, 23.5 and $90.4 \mathrm{kDa}$ should be encoded by this stretch of DNA. Minicell analysis of specific subclones comprising this particular sfa-region exhibited proteins, corresponding in size to the molecular weights deduced from nucleotide sequence (data not shown). Although there is no information on processing of precursors into mature proteins for these ORFs, we speculate that all three proteins contain leader sequences (see Fig. 5). 


\begin{tabular}{|c|c|c|c|}
\hline Glyllodiangnalea & 60 & 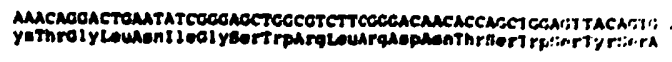 & \\
\hline 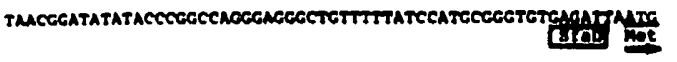 & 120 & 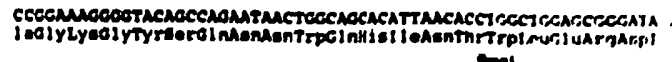 & \\
\hline 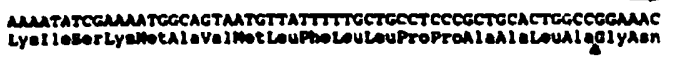 & 1nO & 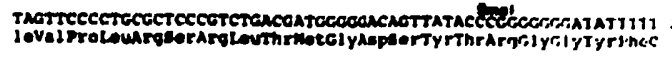 & \\
\hline 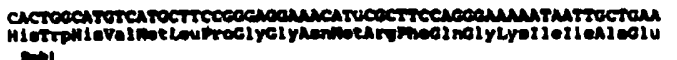 & 240 & 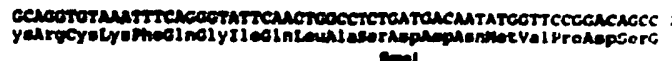 & \\
\hline 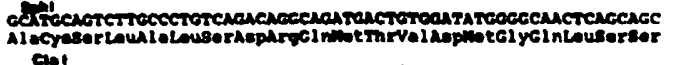 & 300 & 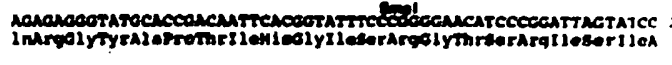 & \\
\hline 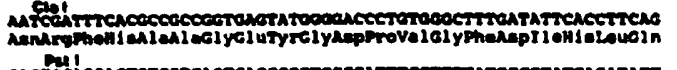 & 360 & 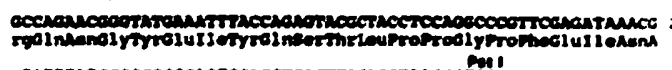 & \\
\hline 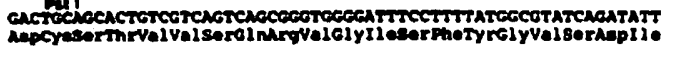 & 420 & 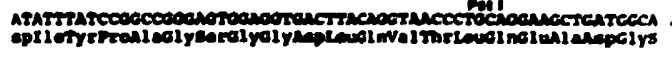 & 2 \\
\hline 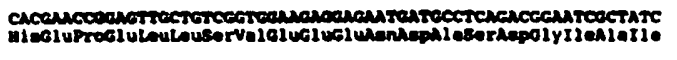 & 410 & 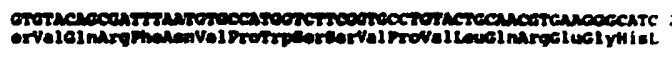 & \\
\hline 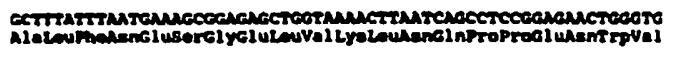 & 540 & 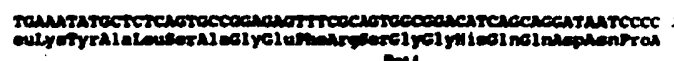 & \\
\hline 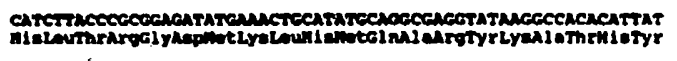 & 600 & 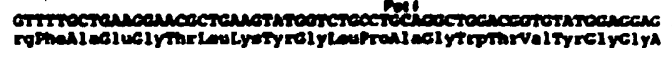 & 2 \\
\hline 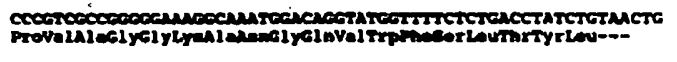 & 660 & 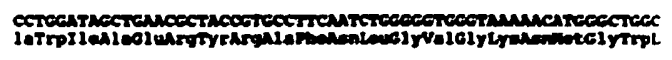 & 2760 \\
\hline 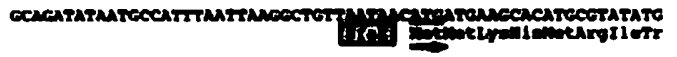 & 720 & coennecocostrs & 2 \\
\hline 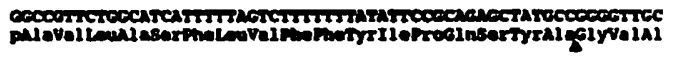 & 740 & 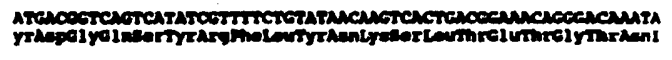 & 28 \\
\hline 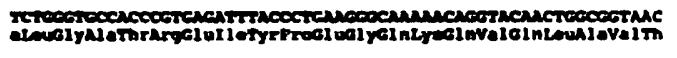 & 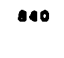 & 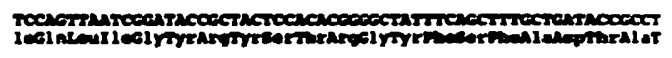 & \\
\hline 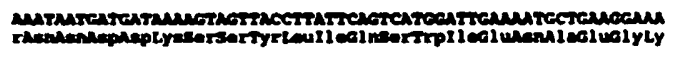 & 900 & 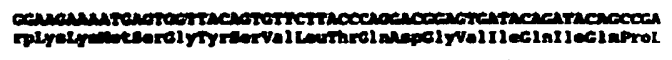 & 30 \\
\hline 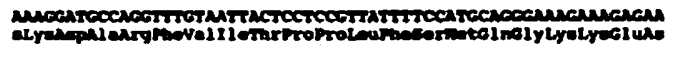 & 90 & poestrucusucosece & 10 \\
\hline 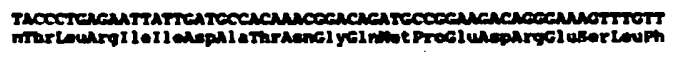 & 1020 & sorractioce & 3 \\
\hline 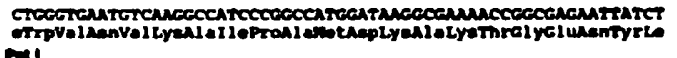 & 1080 & 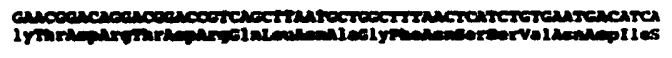 & נו \\
\hline 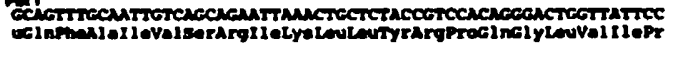 & 1140 & $\operatorname{cosex}$ & \\
\hline 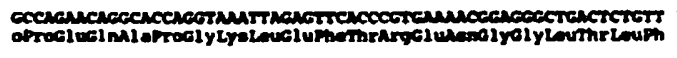 & 1200 & rere & \\
\hline 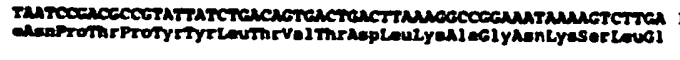 & 1260 & 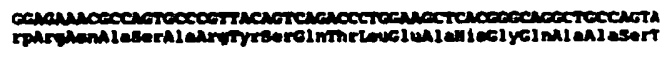 & 3 \\
\hline 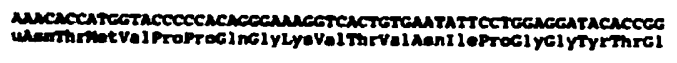 & $\$ 320$ & 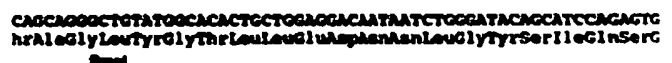 & \\
\hline 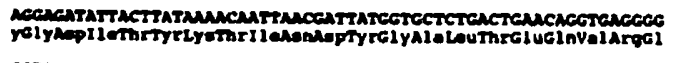 & 1380 & 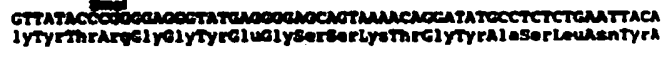 & \\
\hline 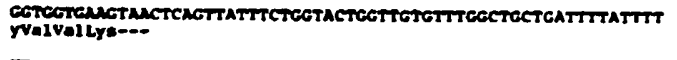 & 144 & 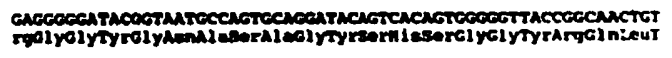 & \\
\hline 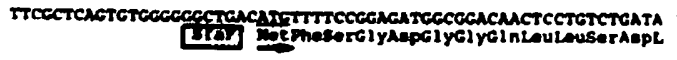 & 150 & 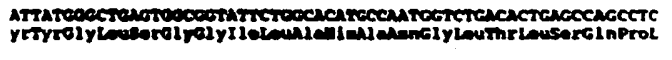 & \\
\hline 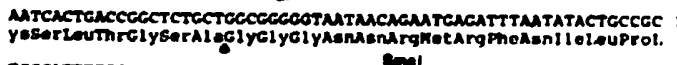 & 1560 & rece & \\
\hline 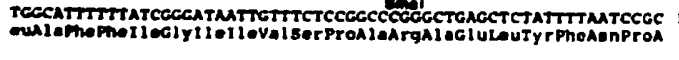 & 1 & 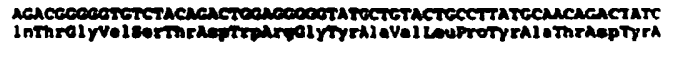 & \\
\hline 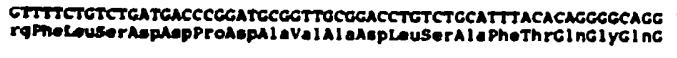 & inan & 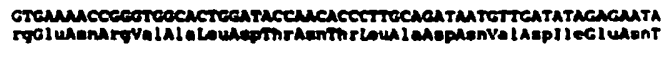 & \\
\hline 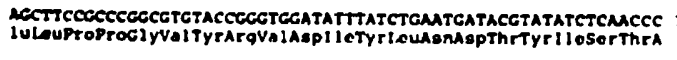 & in & 280 & \\
\hline 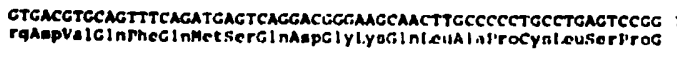 & In & 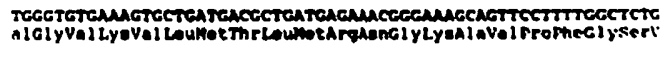 & \\
\hline ECCGGGTATGGAGAGACTCCCGC & IRT, & 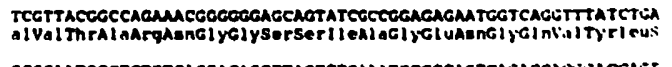 & \\
\hline & 1 & & \\
\hline 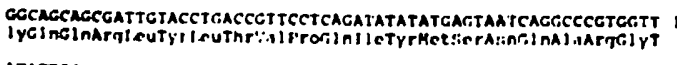 & & 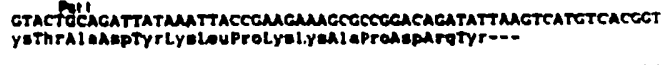 & 1000 \\
\hline 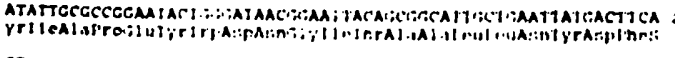 & s.) & 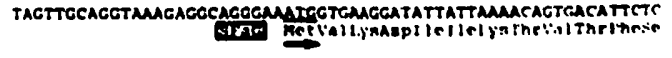 & \\
\hline
\end{tabular}

Fig. 5. Nucleotide sequence of genes sfa D, sfaE, and sfa F. The amino acid residues are given below. The putative cleavage sites of the leader sequences are marked by a triangle. Important restriction sites are indicated.

\section{Discussion and conclusions}

In this report, we have presented data on the genetic organization of the entire E. coli $S$ fimbrial adhesin determinant (sfa) and demonstrated that nine sfa-specific genes are situated on a $7.9 \mathrm{~kb}$ DNA region. In Fig. 6 in sfa gene cluster is compared with the 


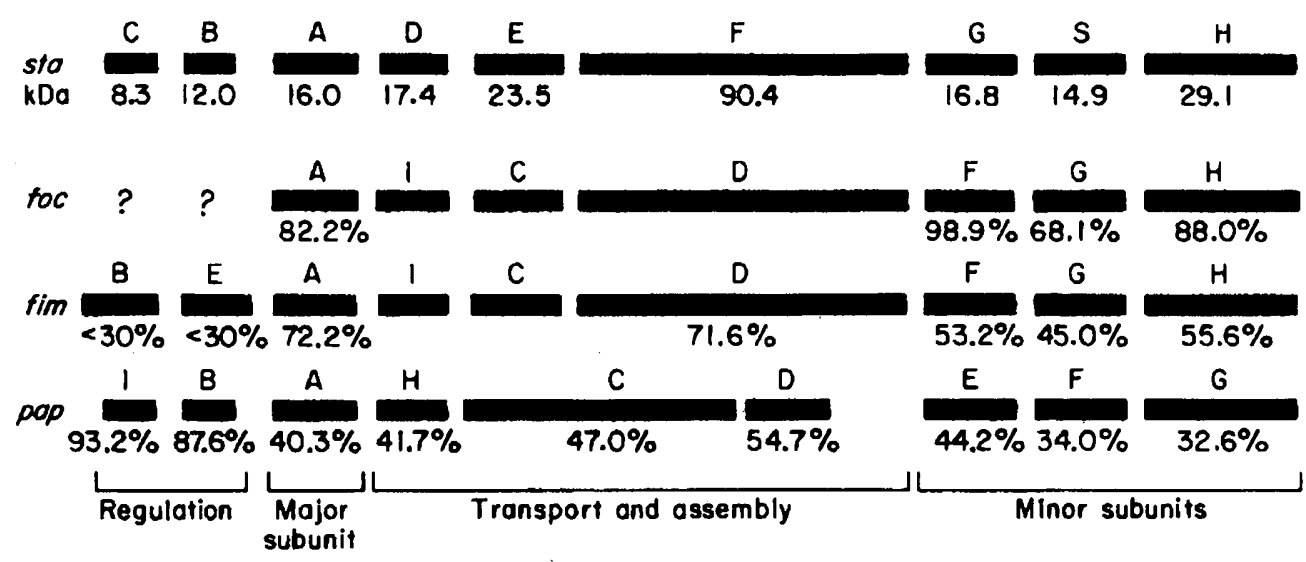

Fig. 6. Comparison of gene clusters encoding $S$ fimbrial adhesin (sfa), F1 C fimbriae (foc), type 1 fimbriae (fim), and P fimbriae, serotype F13 ( $p a p)$. Cistrons, designated by capital letters, are shown. The indicated percentages refer to the degree of homology of the proteins to the corresponding Sfa gene products on basis of identical amino acids or amino acids of similar properties (see Schmoll et al. ${ }^{11}$ ). The PapD protein is compared to the SfaE product (see text). Molecular masses of mature Sfa specific proteins are given (kDa). Functional regions are indicated.

determinants coding for F1C fimbriae, $\mathrm{P}$ fimbriae and type I fimbriae termed foc, pap and fim respectively ${ }^{3.7-9}$ (for review see Hacker ${ }^{4}$ ). It is obvious from the literature that the genetic composition of different adhesin determinants is similar. Different regions of the determinants that code for the major fimbrillin (pilin) subunits and for minor fimbrillin proteins, including the corresponding adhesin proteins, can be distinguished. In addition, sequences necessary for transport and assembly functions as well as regions involved in the regulation of transcription can be identified.

Sequence comparison between the sfa and pap gene clusters shows that there is strong homology between the regulatory genes (papl, B and sfa $\mathrm{C}, \mathrm{B}$ ) while, interestingly, the remaining portions do not exhibit any significant sequence similarities (Fig. 6). P fimbrial gene clusters coding for serotypes other than the pap determinant also exhibit strong homology to this particular sfa-region. ${ }^{18.19}$ Besides sequence homology between P-fimbrial regulatory elements and the proximal sfa-region, a similar arrangement of the direction of transcription of the respective genes can be observed. ${ }^{19-21}$ The relationship of the pap and sfa regulatory region is further corroborated by the fact that the genes $s f a \mathrm{~B}, s f a \mathrm{C}$ and $p a p \mathrm{~B}, p a p \mid$ are able to transcomplement each other. ${ }^{22} \mathrm{~A}$ divergent promoter arrangement similar to the pap and sfa determinants has also been described for regulatory elements of the K99 fimbriae determinant $(f a n)$, although no sequence homology to pap or sfa genes exists. ${ }^{23}$ For the F1C determinant $(f o c)$, it has been shown by genetic analysis and by DNA-DNA hybridization studies ${ }^{24-26}$ that over the whole gene cluster a strong homology to the sfa determinant can be observed, including the proximal part of the gene clusters, suggesting a homologous regulatory region.

In addition we have described three promoter regions which are situated in the proximal part of the sfa determinant. As already mentioned above, two of these, $P_{B}$ and $P_{C}$, show very good promoter consensus sequences ${ }^{27}$ (see Fig. 2). One promoter, $P_{A}$, is situated in front of the sfaA structural gene. Such a promoter is missing in front of the structural $P$ fimbrial gene pap $A^{19-21.28}$ but is present in front of the type I specific structural gene fim $A{ }^{29,30}$ It is interesting to note that the two regulatory genes fim $B$ and fim $\mathrm{E}$ of the type I fimbrial determinant do not exhibit any homology to the regulatory genes of $\mathrm{S}$ fimbriae $s f a \mathrm{~B}$ and $s f a \mathrm{C},{ }^{30}$ but the fimbrial structural genes $s f a \mathrm{~A}$ 
and $\operatorname{fim} A$ are very similar. We speculate that the presence of promoters in front of sfa $A$ and fim $A$ may reflect this relatedness between type $I$ and $S$ subunit genes.

The relatedness of sfa- and fim-specific subunit genes is restricted to the cistrons encoding major fimbrillins (see Fig. 6). The genes coding for the S specific minor subunit proteins show a high degree of homology to the corresponding region of the foc determinant ${ }^{11}$ (Van Die et al., unpublished data) but they differ from those of the pap and fim gene clusters (for review see Hacker ${ }^{4}$ ). These data confirm our previous observations ${ }^{24-26}$ that $S$ and F1C fimbrial gene clusters represent a family of adhesin determinants, as also described for the P/Prs group ${ }^{35,36}$ and the MS-agglutinating type I family. ${ }^{5}$

In addition to the regions coding for major and minor subunits and for regulatory proteins, at least three proteins are encoded by the central parts of $P, S$ and type $I$ determinants. ${ }^{9.31-34}$ The Sfa specific stretch of DNA between the genes sfaA and sfa G also codes for three gene products (see Fig. 5): SfaD (17.4 kDa), which forms a subunit like structure, $\mathrm{SfaE}(23.5 \mathrm{kDa})$ and $\mathrm{SfaF}(90.4 \mathrm{kDa})$. Proteins similar in size to $S f a F$, encoded by the type $I$ and $P$ fimbrial determinants, represent outer membrane proteins which apparently anchor the corresponding fimbrial adhesin complexes to the cell wall. ${ }^{9,31,32}$ SfaF, which exhibits $71 \%$ homology to the anchor protein of type I fimbriae, FimD, may perform a similar function. The high degree of homology between SfaF and FimD may be the reason for the hybridization observed following DNA-DNA hybridizations between $S$ and type I fimbrial gene clusters. ${ }^{24}$

As shown recently, the proteins $\mathrm{PapD}$ and $\mathrm{PapH}$ of $\mathrm{P}$ fimbriae are also involved in biogenesis of the fimbrial adhesin structure. $\mathrm{PapH}$, which forms a subunit like structure, is situated at the base of the fimbriae and terminates fimbrial biogenesis. ${ }^{33}$ In contrast, PapD functions as a transporter responsible for the transfer of subunit proteins through the periplasmic space. ${ }^{34}$ From the sequences given in Fig. 5, we suggest that the subunit-like protein SfaD may share common features with $\mathrm{PapH}$ while SfaE could be equivalent to PapD. The corresponding genes, however, are situated at different positions in the determinants. The papD gene is situated downstream of the large gene pap C, while sfaE (and also fim $\mathrm{C}$ ) is encoded by a DNA region upstream of the large gene responsible for the anchor protein (Fig. 6).

The highly conserved arrangement of cistrons of the various fimbrial adhesin determinants is an interesting feature, since there is only limited overall sequence homology, with the exception of the sfa and foc gene clusters. When the determinants are divided into functional regions (see Fig. 6), it is apparent that sequence homology is restricted to certain parts, which could be defined as 'cassettes'. The sfa and foc determinants seem to be closely related. However, only the regulatory cassettes of sfa and pap, and the major subunits and large anchor proteins of fim and sfa, seem to be closely related. These observations lead to speculations about the evolution of fimbrial adhesin gene clusters. Possibly diversity has been generated by combining cassettes of a few ancestral determinants. By this mechanism new fimbrial determinants are created which are selected according to their usefulness for the strains. This hypothesis would explain the wide spectrum of different adhesin determinants, described so far.

\section{Materials and methods}

Bacterial strains, plasmids and phages. The sfa determinant was originally cloned from $E$. coli strain 536, a urinary tract isolate $(06: \mathrm{K} 15: \mathrm{H31})$, described elsewhere. ${ }^{6,37}$ Plasmid pANN 801 . 13 carries the entire sfa gene cluster (Fig. 1) as described. ${ }^{6.11 .15}$ Plasmids pANN 801-15, and pANN 801-24 have been described recently. ${ }^{6.12}$ Plasmid pANN $801-153$ consists of the vector pACYC184 and a $1.4 \mathrm{~kb}$ Ecol-Nrul fragment coding for SfaC (see Fig. 1). The bacterial strains, 
Table 1 Bacterial strains, cloning vectors and phages used

\begin{tabular}{|c|c|c|}
\hline Designation & Description & Reference \\
\hline \multicolumn{3}{|c|}{ Escherichia coli K-12 strains } \\
\hline HB101 & $\begin{array}{l}\mathrm{F}^{-}, \text {hsdS20 }\left(\mathrm{r}_{\mathrm{B}}-, \mathrm{m}_{\mathrm{B}}-\right), \operatorname{rec} \mathrm{A} 13, \text { ara }-14 \\
\text { pro } 2, \text { lac } \mathrm{Y} 1, g a / \mathrm{K} 2, \text { rps } \mathrm{L} 20\left(\mathrm{Sm}^{\prime}\right) \\
\quad x y /-5, m t /-1, \text { sup } \mathrm{E} 44\end{array}$ & 38 \\
\hline JM103 & $\begin{array}{l}\Delta(\text { (ac, pro ) , thi, rpsL20, sup } \mathrm{E} \text {, end } \mathrm{A}, s b c \mathrm{~B} \\
\text { hsd } \mathrm{R}, \mathrm{F}^{\prime} \text { (tra D36, proA, B, laclq) }\end{array}$ & 39 \\
\hline MC4100 & $\begin{array}{l}\mathrm{F}^{-}, \text {ara } \mathrm{D} 139, \Delta\left(\arg \mathrm{F}^{-}, / a c\right) \cup 169 \text { rps } \mathrm{L} 150, \\
\text { re/A1, deo } \mathrm{C} 1, p t s \mathrm{~F} 25, \text { rbs } \mathrm{R}, \text { flb B5301 }\end{array}$ & 40 \\
\hline MBM 7014 & $\begin{array}{l}\mathrm{F}^{-}, \operatorname{ara} \mathrm{C}_{\mathrm{am}}, \operatorname{ara} \mathrm{D}, \Delta\left(\arg \mathrm{F}^{-} \text {lac }\right) \cup 169 \text { trp }_{\mathrm{am}} \\
\mathrm{ma} / \mathrm{B}_{\mathrm{am}}, \operatorname{rps} \mathrm{L}, \mathrm{re} / \mathrm{A}, \text { thi }\end{array}$ & 40 \\
\hline CC118 & $\begin{array}{l}\operatorname{ara} \mathrm{D} 139, \Delta(a r a, l e u) 7697, \Delta / a c \times 74 \text { phoA } 20, \\
\text { ga/ } \mathrm{E}, \text { gal } \mathrm{K}, \text { thi, rps } \mathrm{E}, \text { rpo } \mathrm{B}, \arg \mathrm{E}_{\mathrm{am}}, \operatorname{rec} \mathrm{A} 1\end{array}$ & 16 \\
\hline \multicolumn{3}{|l|}{ Cloning vectors } \\
\hline $\begin{array}{l}\text { pCB267 } \\
\text { pBR322 }\end{array}$ & $\begin{array}{l}\text { b/a, '/ac Z, 'phoA } \\
\text { bla, tet }\end{array}$ & $\begin{array}{l}16 \\
41\end{array}$ \\
\hline pACYC184 & cat, tet & 42 \\
\hline pUC8 & $b / a, / a c Z$ & 43 \\
\hline M13-mp18/mp19 & DNA sequencing & 39 \\
\hline \multicolumn{3}{|l|}{ Phages } \\
\hline $\begin{array}{l}\lambda \mathrm{p} / \mathrm{ac} \mathrm{Mu3} \\
\lambda \mathrm{pMu} 507-3\end{array}$ & $a t t^{-}, \operatorname{lacZ} / a c Y, \mathrm{MuA}^{+}, i m m 21$, Mucs & 44,45 \\
\hline
\end{tabular}

cloning vectors and phages used are listed in Table 1. The phages are described by Bremer et al. ${ }^{44,45}$ All $E$. coli strains were $\mathrm{K}-12$ derivatives.

Media and reagents. Bacterial strains were grown on Luria Bertani (LB) agar plates or in liquid LB medium, as described. ${ }^{6}$ For maintenance of plasmids $50 \mu \mathrm{g}$ ampicillin per $\mathrm{ml}$, or $20 \mu \mathrm{g}$ chloramphenicol per $\mathrm{ml}$ were added. For detection of the Lac phenotype, LB medium was supplemented with IPTG (isopropylthiogalactoside, $0.05 \mathrm{mM}$ ) and X-Gal (5 bromo-4-chloro3-indoloyl-galactoside, $0.01 \%$ ) or MacConkey agar was used. The production of alkaline phosphatase was detected on XP-plates containing $20 \mu \mathrm{g}$ of 5-bromo-4-chloro-3-indolyl phosphate per $\mathrm{ml}$. Restriction enzymes, T4 Ligase and Klenow enzyme were purchased from Boehringer (Germany). Antibiotics were a gift from Bayer (Germany). Reagents for growth media were obtained from Oxoid (Germany). All other chemicals were obtained from Sigma (Germany)

Recombinant DNA techniques. Plasmid DNA was isolated by the method of Birnboim and Doly. ${ }^{46}$ Large-scale preparations were further purified over $\mathrm{CsCl}$ gradients, as described..$^{37}$ DNA was cleaved with restriction enzymes according to the manufacturer's instructions, and separated on $1 \%$ agarose gels, as described by Maniatis et al. ${ }^{47}$ Isolation of DNA fragments from agarose gels was performed by the freeze-squeeze method according to Thuring et al. ${ }^{48}$ Ligation of DNA fragments was carried out, as described. ${ }^{47}$ Competent cells for DNA transformation were prepared by $\mathrm{CaCl}_{2}$ method. ${ }^{49}$

Construction of recombinant plasmids. The recombinant plasmids indicated in Fig. 1 were constructed by ligating suitable sfa-specific fragments directly into pACYC184 (pANN801-15 and pANN801-153) or into the Smal site of the pUC8 polylinker sequence (pANN801-24). Cloning vector $\mathrm{pCB} 267^{16}$ and strain $\mathrm{CC} 118$ were used for the construction of sfa-phoA fusions. As indicated in Fig. 4, suitable sfa specific DNA fragments ligated into the cloning vector pCB267 resulted in the sfa-phoA recombinant DNAs. The recombinant plasmid pTTS267-45 carries the linker sequence from pCB267 inserted into the Smal-site at map position 1.65 (Fig. 1). Although the sfa $B$ gene was out of frame, the putative promoter $P_{B}$, situated in front of sfa $B$, was still active in this recombinant DNA.

DNA sequencing and oligonucleotide synthesis. DNA sequencing was performed by the dideoxy chain termination method of Sanger et al., ${ }^{50}$ using $\alpha^{32}$ P-ATP (Amersham-Buchler, 
Germany). Either single stranded recombinant M13 phage DNA or double stranded DNA of recombinant pUC plasmids were used..$^{43}$ Cloning of DNA fragments in M13 phage vector and isolation of single stranded DNA were carried out as described. ${ }^{39.47}$ The primers used were synthetic oligodeoxyribonucleotides, prepared by an automated phosphoramidite coupling method. ${ }^{51}$ Sequencing was carried out with a T7 sequencing kit (Pharmacia, Germany), including universal primer. ${ }^{43}$ As a recipient strain for recombinant DNA, JM 103 was used.

Determination of the insertion points of Tn 5 mutants. In order to determine the exact position of Tn5 insertions into the pANN801 - 13, derivatives pANN801-13/Tn5-014, pANN801-13/Tn5 032, pANN801-13/Tn5-036 were sequenced. The DNA was first cleaved with the restriction enzyme Hpal and suitable DNA fragments carrying 195 base pairs Tn5-specific sequence together with the sfa-specific region were ligated into the vectors pUC18 and pUC19. The DNA sequences of the insertion points were determined by the plasmid sequence technique with the help of the DNA sequencing kit from Pharmacia.

Computer analysis. General compilation and analysis of DNA sequences was performed with the UWGCG programs obtained from Devereux..$^{22}$ For comparison of proteins the software package PC Gene was used (Intelli Genetics, Switzerland). ${ }^{53}$

Preparation of phage stock solutions. As indicated by Bremer et al ${ }^{44.45}$ nearly $10^{8}$ phage particles were mixed with $10^{8}$ bacteria ( $\lambda$ p/ac Mu3 was mixed with strain MC 4100 , $\lambda$ pMu507. 3 with strain MBM 7014), spotted on soft agar plates and incubated for $12 \mathrm{~h}$ at $37^{\circ} \mathrm{C}$. The plates were then incubated with $5 \mathrm{ml} \mathrm{SM}$-buffer for $4 \mathrm{~h}$ at $4^{\circ} \mathrm{C}$. The supernatant which contains the phage particles, was removed and stored at $4^{\circ} \mathrm{C}$.

Transposition assays of $\lambda$ plac $M u$ phages. The $\lambda$ plac Mu phage transposition was performed according to Bremer $e t$ al ${ }^{44.45}$ Briefly, the plasmid-bearing strain MC 4100 was infected with a mixed stock of $\lambda$ plac Mu3 and $\lambda$ pMu507-3 and plated on MacConkey agar plates. After overnight incubation at $37^{\circ} \mathrm{C}$ the cells were scraped from the plates, washed, and then grown to exponential phase. A phage lysate was prepared by induction with UV-irradiation and used to transduce a K-12 $\mathrm{Lac}^{-}$strain with selection of $\mathrm{Lac}^{+}$and the plasmid-borne resistance. The position of insertion was determined by suitable digestions of the recombinant DNA consisting of phage and plasmid specific sequences.

Enzyme assays. The $\beta$-galactosidase units were determined by the method of Miller. ${ }^{54} \mathrm{~A}$ quantitative assay for alkaline phosphatase was carried out according to Michaelis et al. ${ }^{17}$

The authors wish to thank $M$. Wuenscher for critical reading of the manuscript and $H$. Kurz for editorial assistance. The work was supported by the Deutsch Forschungsgemeinschaft (DFG Ha 1434/1-7).

\section{References}

1. Svanborg-Eden C. Hagberg L, Hanson LA et al. Bacterial adherence-a pathogenic mechanism in urinary tract infections caused by Escherichia coli. Prog Allergy 1983; 33: 175-88.

2. Korhonen TK, Valtonen MV. Parkkinen $J$ et al. Serotypes, hemolysin production, and receptor recognition of Escherichia coli strains associated with neonatal sepsis and meningitis. Infect Immun 1985; 48: 486-91.

3. Lindberg F, Lund B, Normark S. Gene products specifying adhesion of uropathogenic Escherichia coli are minor components of pili. Proc Natl Acad Sci USA 1986; 83: 1981-5.

4. Hacker J. Genetic determinants coding for fimbriae and adhesins of extraintestinal Escherichia coli. Curr Top Microbiol Immunol 1990; 151: 1-27.

5. Orskov F, Orskov I. Serology of Escherichia coli fimbriae. Prog Allergy 1983; 33: 80-105.

6. Hacker J, Schmidt G, Hughes C, Knapp S, Marget M, Goebel W. Cloning and characterization of genes involved in the production of mannose-resistant, neuraminidase-susceptible $(X)$ fimbriae from a uropathogenic O6:K15: H31 Escherichia coli strain. Infect Immun 1985; 47: 434-40.

7. Van Die I, van Geffen B, Hoekstra W. Bergmans H. Type $1 \mathrm{C}$ fimbriae of a uropathogenic Escherichia coli strain. Cloning and characterization of genes involved in the expression of the $1 \mathrm{C}$ antigen and nucleotide sequence of the subunit gene. Gene 1984; 34: 187-96.

8. Eisenstein BI, Sweet DS, Vaughn V, Friedman DI. Integration host factor is required for the DNA 
inversion that controls phase variation in Escherichia coli. Proc Natl Acad Sci USA 1987; 84: 6506 10.

9. Klemm P, Christiansen G. The fimD gene required for cell surface lacalization of Escherichia coli type 1 fimbriae. Mol Gen Genet 1990; 220: 334-8.

10. Moch T, Hoschützky H, Hacker J, Kröncke K, Jann K. Isolation and characterization of the alphasialyl-beta-2,3-galactosyl-specific adhesin from fimbriated Escherichia coli. Proc Natl Acad Sci USA 1987; 84: 3462-6.

11. Schmoll T, Hoschützky H, Morschhäuser J, Lottspeich F, Jann K, Hacker J. Analysis of genes coding for the sialic-acid-binding adhesin and two other minor fimbrial subunits of the S-fimbrial adhesin determinant of Escherichia coli. Mol Microbiol 1989; 3: 1735-44.

12. Hacker J, Schmoll T, Ott $M$ et al. Genetic structure and expression of virulence determinants from strains of Escherichia coli. In: Kass E, Svanborg-Eden C, eds. Studies in infectious disease research. Host parasite interactions in urinary tract infection. Chicago: University of Chicago Press, 1989; 144-56.

13. Schmoll T. Hacker J, Goebel W. Nucleotide sequence of the $s f a A$ gene coding for the S-fimbrial protein subunit of Escherichia coli. FEMS Microbiol Lett 1987; 41: 229-35

14. Morschhäuser J, Hoschützky H, Jann K, Hacker J. Functional analysis of the sialic-acid binding adhesin SfaS of pathogenic Escherichia coli by site-specific mutagenesis. Infect Immun 1990; 58: 2133-8.

15. Schmoll T, Ott M, Oudega B, Hacker J. Use of a wild-type gene fusion to determine the influence of environmental conditions on the expression of the $S$ fimbrial adhesins in an Escherichia coli pathogen. J Bacteriol 1990; 172: 5103-11.

16. Schneider K, Beck CF. Promoter-probe vectors for the analysis of divergently arranged promoters. Gene 1986; 42: 37-48.

17. Michaelis S, Inouye H, Oliver D, Bechwith J. Mutations that alter the signal sequence of alkaline phosphatase in Escherichia coli. J Bacteriol 1983; 154: 366-74.

18. Rhen $M$, Väisänen-Rhen $V$. Nucleotide sequence analysis of a $P$ fimbrial regulatory element of the uropathogenic Escherichia coli strain KS71 (04:K12). Microbial Pathogenesis 1987; 3: 387-91.

19. Blyn LB, Braaten BA, White-Ziegler CA, Rolfson DH, Low DA. Phase-variation of pyelonephritisassociated pili in Escherichia coli, evidence for transcriptional regulation. EMBO J 1989; 8: 613-20.

20. Båga M, Göransson S, Normark S, Uhlin BE. Transcriptional activation of a pap virulence operon from uropathogenic Escherichia coli. EMBO J 1985; 4: 3887-93.

21. Båga $M$, Göransson $S$, Normark $S$, Uhlin BE. Processed mRNA with differential stability in the regulation of Escherichia coli pilin expression. Cell 1988; 52: 197-206.

22. Göransson $M$, Forsman $K$, Uhlin BE. Functional and structural homology among regulatory cistrons of pili-adhesin determinants in Escherichia coli. Mol Gen Genet 1988; 212: 412-17.

23. Roosendahl E, Boots $M$, de Graaf FK. Two novel genes $\operatorname{fan} A$ and $\tan B$, involved in the biogenesis of K99 fimbriae. Nucleic Acids Res 1987; 15: 5973-84.

24. Ott M, Schmoll T, Goebel W, van Die I, Hacker J. Comparison of the genetic determinant coding for the S-fimbrial adhesin (sfa) of Escherichia coli to other chromosomally encoded fimbrial determinants. Infect Immun 1987; 55: 1940-3.

25. Ott M, Hoschützky H, Jann K, van Die I, Hacker J. Gene clusters for S-fimbrial adhesin (sfa) and F1C fimbriae $(f o c)$ of Escherichia coli: comparative aspects of structure and function. $J$ Bacteriol 1988; 170: 3983-90.

26. Riegman N, Kusters R, van Veggel H et al. F1C fimbriae of uropathogenic Escherichia coli: genetic and functional organization of the foc gene cluster and identification of minor subunits. $J$ Bacteriol 1990; 172: 114-20.

27. McClure W. Mechanism and control of transcription in procaryotes. Annu Rev Biochem 1985; 54: 171-204.

28. Båga M, Normark S, Hardy I et al. Nucleotide sequence of the papA gene encoding the Pap pilus subunit of human uropathogenic Escherichia coli. J. Bacteriol $1984 ; 157: 330-3$.

29. Klemm P. The fim A gene encoding the type I fimbrial subunit of Escherichia coli: nucleotide sequence and primary structure of the protein. Eur J Biochem 1984; 143: 395-9.

30. Klemm $\mathbf{P}$. Two regulatory fim genes, fim $\mathrm{B}$ and fimE, control the phase variation of type I fimbriae in Escherichia coli. EMBO J 1986; 5: 1389-93

31. Norgren M, Baga M, Tennent JM, Normark S. Nucleotide sequence, regulation and functional analysis of the papC gene required for cell surface localization of Pap pili of uropathogenic Escherichia coli. Mol Microbiol 1987; 1: 169-78.

32. Riegman N, Acton D, Sakkers R, Van Die I, Hoekstra W, Bergmans H. Functional analysis of the fso C gene product of the F7, (fso) fimbrial gene cluster. Mol Microbiol 1990; 4:101-6.

33. Baga $M$, Norgren $M$, Normark S. Biogenesis of $E$. coli Pap pili: $\mathrm{PapH}$, a minor subunit involved in cell anchoring and length modulation. Cell 1987; 49: 241-51.

34. Lindberg F, Tennent JM, Hultgren SJ, Lund B, Normark S. PapD a periplasmic transport protein in $P$ pilus biogenesis. J Bacteriol 1989; 171: 6052-8.

35. Van Die I, Hoekstra W. Bergmans H. Analysis of the primary structure of P-fimbrillins of uropathogenic Escherichia coli. Microbial Pathogenesis 1987; 3: 149-54.

36. Lund B, Marklund BI, Strömberg N, Lindberg F, Karlsson KA, Normark S. Uropathogenic Escherichia coli can express serologically identical pili of different receptor binding specificities. Mol Microbiol 1988; 2: 255-63 
37. Berger H, Hacker J, Juarez A, Hughes C, Goebel W. Cloning of the chromosomal determinants encoding hemolysin production and mannose-resistant haemagglutination in Escherichia coli. J Bacteriol 1982; 157: 330-3.

38. Boyer HW, Roulland-Dussoix D. A complementation analysis of the restriction and modification of DNA in Escherichia coli. J Mol Biol 1969; 41: 459-72.

39. Hu N, Messing J. The making of strand-specific M13 probes. Gene 1982; 17: 271-7.

40. Casadaban MJ, Chou J, Cohen SN. In vitro gene fusions that join an enzymatically active $\beta$ galactosidase segment to amino-terminal fragments of exogenous proteins: Escherichia coli plasmid vectors for the detection and cloning of translational initial signals. J Bacteriol 1980; 143: 971-80.

41. Bolivar F, Rodriguez RL, Green PJ, Betlach MC, Heyneker H, Boyer HW. Construction and characterization of new cloning vehicles. II. A multipurpose cloning system. Gene 1977; 2: 95-113.

42. Chang ACY, Cohen SN. Construction and characterization of amplifiable multicopy DNA cloning vehicles derived from the P15A cryptic plasmid. J Bacteriol 1978; $134: 1141-56$.

43. Vieira $\mathrm{J}$, Messing $\mathrm{J}$. The pUC plasmids, an $\mathrm{M} 13 \mathrm{mp7}$-derived system for insertion and mutagenesis and sequencing with synthetic universal primers. Gene 1982; 19: 259-68.

44. Bremer E, Silhavy TJ, Weisemann JM, Wienstock GM. iplac Mu: a transposable derivative of bacteriophage lambda for creating lac Z protein fusions in a single step. J Bacteriol 1984; 158: 108493.

45. Bremer E, Silhavy TS, Weinstock GM. Transposable $\lambda$ plac Mu bacteriophages containing lac Z operon fusions and Kanamycin resistance insertions in Escherichia coli. J Bacteriol 1985; 162: 1092-9.

46. Birnboim HC, Doly J. A rapid extraction procedure for screening recombinant plasmid DNA. Nucleic Acids Res 1979; 7: 1513-23.

47. Maniatis T, Fritsch EF, Sambrook S. Molecular cloning. A laboratory manual. Cold Spring Harbor, Cold Spring Harbor Laboratory Press, 1982.

48. Thuring RWF, Sander JP, Borst B. A freeze-squeeze method for recovering long DNA from agarose gels. Anal Biochem 1975; 66: 213-20.

49. Lederberg $E$, Cohen SN. Transformation of Salmonella typhimurium by plasmid deoxyribonucleic acid. J Bacteriol 1974; 119: 1072-4.

50. Sanger F, Nicklen S, Coulson AR. DNA sequencing with chain-terminating inhibitors. Proc Natl Acad Sci USA 1977; 74: 5463-7.

51. Beaucage SL, Caruthers MH. Deoxynucleoside phosphoramidites: a new class of key intermediate for deoxypolynucleotide synthesis. Tetrahedron Lett 1981; 22: 1859-62.

52. Devereux J. UWGCG computer programs. University of Wisconsin, 1984.

53. Intelli Genetics. Genofit software package. Geneva, 1986.

54. Miller J. Experiments in molecular genetics: a laboratory manual. Cold Spring Harbor: Cold Spring Harbor Laboratory Press, 1972. 